\section{The biologist's eye on human affairs}

\author{
Robert Attenborough
}

Biology and Society. Editor D.F. Roberts Eugenics Society, 69 Eccleston Square, London SWIV IPJ, UK. 4/yr. £14, \$27.

BIOlogy and society interact in many different ways, but Biology and Society concentrates on interactions involving human reproduction, genetics, demography and health. In this it differs from some similarly titled publications, but it does invite comparison especially with the Journal of Biosocial Science.

Modestly enlarged, and now with an editorial board, Biology and Society is the reincarnation of the Bulletin of the Eugenics Society. The Bulletin, which did not attempt to be a major research journal (unlike the Journal of Biosocial Science), acted mainly as the Society's internal forum for news and discussion. Biology and Society has taken over this domestic role, and a large proportion of its space is devoted to editorials, lecture texts and summaries, conference notices and reports, the Society's news, book reviews and notes on articles in other publications.

The journal is, in other words, something of a hotchpotch. Quite a few of the main items, such as commentaries on the Warnock Committee Report and the Mexico City Population Conference, are substantial, balanced and interesting. Many of the smaller pieces too, including book reviews, are well worthwhile. But certain contributions, including a disappointingly unincisive lecture by a former British Cabinet Secretary, seem less commendable. And some minor entries, such as the less detailed conference reports where we learn little more than that soand-so spoke on the subject of such-andsuch, are unlikely to be useful beyond a limited circle.

Unlike its predecessor, Biology and Society also publishes research reports, and in this respect its role seems less clearly differentiated from that of the Journal of Biosocial Science. The reports in Biology and Society are generally shorter, but their range of topics is similar, and the need for a new outlet is therefore not obvious - unless it is a matter of sheer volume. Nonetheless, some interesting papers have appeared, for example on smoking, genetic counselling, infertility and infant mortality.

The journal, especially in its new form, is evidently trying to appeal to readers beyond the Eugenics Society, and the major institutional libraries needing to cover this field will wish to subscribe. But in two particular respects, its role seems not (yet) to be clearly defined, which may discourage less committed libraries and individuals. The first is that the Society's objectives beyond the support of academic research are stated in very general terms - who could disagree with the aim of fostering "a responsible attitude to parenthood", for example? - so that outsiders can be forgiven for uncertainty about the extent to which Francis Galton's intellectual legacy weighs on the journal's shoulders.

The other problem concerns the nature of the intended audience. In its emphasis on news and topical discussion, often nontechnically presented, it sometimes seems to seek an audience beyond academia (as Anthropology Today does in contrast to the more specialist Man). Indeed the potential for such a role is very real. At other times, however, both content and style are more specifically academic. So different parts of the journal appeal to different readers: but then - though their place in the market is vastly different the same may be said of publications such as Nature.

Robert Attenborough is a Lecturer in Biological Anthropology in the Department of Prehistory and Anthropology, A.D. Hope Building, Australian National University, GPO Box 4 , Canberra, ACT 2601, Australia.

\section{Technology in time}

\section{Colin A. Russell}

History and Technology: An International Journal. Executive Editor Pietro Redondi. Harwood. 4/yr. North America $\$ 70$ (corporate), $\$ 60$ (institutional), $\$ 30$ (individual); UK $£ 58$ (corporate), $£ 50$ (institutional), $£ 25$ (individual).

"THE development of gadgets" is one way to describe the history of technology. It would not, however, please the sponsors of this new journal. In the following rather grandiose terms the editor states his objective:

We wish to see technology through its relationship to history by placing it at the center of historical perspective as a variable that is autonomous without being independent of the state of society.

Which means (I think) that he intends to take a hard look at technology in its social context. This is a laudable ambition. Much that used to pass for history of technology was almost entirely insulated from all other kinds of contemporary history. As with the history of science in the past few decades, this "internalist" approach is widely seen today as restrictive, artificial, arbitrary and rather pointless. Merely assembling data on the machine as it has changed through the ages is rather like stamp collecting: fun (if you like it) but of little intellectual content or explanatory power. Another way of putting it is to say that, if history of technology may be properly located within technology itself, then it is equally appropriate to regard it as part of history. History and Technology appears to be trying to do just that and, indeed, to make technology a central theme in history, relating it to all kinds of other trends and happenings.

These concerns are reflected in the journal's format. Four kinds of article are promised. Under "Foundations and Methods" are articles on methodology what historians love to call historiography. "Studies" include specific case histories of technical innovation as well as collective and individual biographies "free from any hagiographical temptations". "Sources" deal, as expected, with documentary sources (in which are curiously included instruments and machines). Finally, "Notes" will communicate news of meetings and programmes, and report upon other initiatives in the subject.

The first two issues followed this format fairly closely with some general reflections on the nature of history and technology, studies on the steam engine in latenineteenth-century France and on mechanics, thermodynamics and locomotive design. The combined third and fourth issue deals with one special theme: technology and economic crises, ranging from the great depression in the Middle Ages, through the Paris Exhibition of 1881 to the American slump of the 1930s. It also includes theoretical discussion on the relation between economics and technical progress, based on a critique of Marx and Schumpeter.

It would be unjust to suggest that History and Technology has the field to itself. An obvious rival is Technology and Culture, though this is more American than the new journal which has a strong European input, especially from France. At the price (Vol. 1 contained 341 pages) it is not outrageously expensive but neither is it cheap.

More pertinent is the question of its intended readership. For those seriously interested in the social history of technology, with an eye to finely judged historical argument, it will be a welcome addition to the periodical literature. If, however, the editorial board wish to address their journal to working scientists, engineers and the like they would do well to look to their house-style. Some of the literary infelicities in the first volume may be attributed to problems of translation. Others, however, are merely the verbal detritus of a new professionalism, an inevitable consequence of which is the development of an in-language. If some of the authors could be persuaded to avoid quite so much sociological and historical jargon their valuable insights would be available to a far wider audience. For an international journal with the exalted aims of this one, that would be no bad thing.

Colin A. Russell is Professor of History of Science and Technology at the Open University, Walton Hall, Milton Keynes MK7 6AA, UK. 